\title{
High Grade Cervical Glandular Intraepithelial Neoplasia
}

National Cancer Institute

\section{Source}

National Cancer Institute. High Grade Cervical Glandular Intraepithelial Neoplasia. NCI

Thesaurus. Code C7675.

Cervical glandular intraepithelial neoplasia characterized by the presence of severe dysplastic changes. 